\title{
1. Introduction to judgment and leadership
}

\section{Anna B. Kayes and D. Christopher Kayes}

Judgment and Leadership: A Multidisciplinary Approach to Concepts, Practice, and Development presents original thinking and addresses age-old concerns regarding the relationship between judgment and leadership. Judgment and leadership are inseparable. Judgment guides every action that a leader takes and underlies every thought, emotion, or justification that leaders form. This volume extends the study of judgment and leadership across disciplinary and conceptual boundaries.

For the first time, the most original and influential thinkers on judgment and leadership contribute to a single volume. The contributors represent a diverse set of disciplines, including critical studies, psychology, political theory, international policy, adult learning theory, management and organizational studies, philosophy, cross-cultural studies, and neuroscience. The result is an engaging look at one of the most important issues facing organizations, politics, and society: leaders and their judgment. The belief that judgment is important in leadership has been discussed (Shotter and Tsoukas, 2014; Tichy and Bennis, 2007a, 2007b) and has long been associated with how leaders solve problems and take action in the face of challenging situations (Dewey, 1933; Simon, 1973). Building on these ideas, the book offers a working definition of judgment that centers on the application of multiple sources of knowledge, including evidence, experience, and expertise, to solve practical problems. This definition sets the groundwork for the book. The book is organized around three questions:

- What is judgment and how is it formed and practiced by leaders?

- What barriers, blind spots, and other factors can lead to bad judgment?

- How do leaders learn to develop judgment?

Part I: Conceptualization and Processes of Leadership Judgment considers what it means to practice judgment by leaders. Judgment is discussed as it relates to cognition, neuroscience, character, political aspirations, and other factors.

Part II: Leadership Judgment Barriers, Blind Spots, and Bad Judgment looks primarily at factors that challenge leaders as they seek to make good judgments. Hubris, the inability to feel regret, lack of awareness of self-interests, situational variables, and context are among the factors that conspire to limit judgment.

Part III: Developing and Learning Leadership Judgment describes how leaders can cultivate better judgment and provides examples of how they learn and develop better judgment. Development and learning have particular relevance in these chapters that discuss a cross-cultural, interpersonal, crisis, and academic context. 


\section{WHY A BOOK ON JUDGMENT AND LEADERSHIP}

Despite differences in views on how to cultivate judgment, there is growing consensus around the fact that judgment is an essential component of leadership (see Akinci and Sadler-Smith, 2019; Graduate Management Admissions Council, 2016; Mintzberg, 2004; Vickers, 1984). Yet the role of judgment in the practice and development of leadership is not well understood. This book offers insights into how judgment is enacted in contemporary leadership studies in at least two important ways.

First, the book helps both integrate judgment with and differentiate judgment from similar concepts and ideas. Judgment is often confused with topics such as decision-making, critical thinking (Errington and Bubna-Litic, 2015), practical wisdom (Wittmer and Fukami, 2017), and procedural knowledge. Further, there are a number of similar concepts associated with, but distinct from, judgment. Klein's (2015) naturalistic decision-making, Schon's (1983) reflective practice, and Sternberg's (Sternberg et al., 2000; Sternberg and Hedlund, 2002) practical intelligence all overlap with but also inform our understanding of judgment. From a developmental perspective, judgment also overlaps with discussions of expertise and its development (see Carter, 2013; Ericsson and Lehmann, 1996; Franklin, 2013) as well as learning from experience (Kolb and Kolb, 2005) and integrative thinking (Tetlock, 1994). This book provides a promising forum for making elements of judgment explicit in leadership and providing a basis for the development of judgment in leaders, especially when they face difficult and complex problems.

Further, leadership studies have tended to focus on techniques and outline essential competencies. A quick review of the research yields a list of competencies and techniques: negotiation, perception management, communication, motivation, and others. But, while leadership techniques are important, exercising judgment - which includes combining experience, knowledge, understanding of when to use techniques, and discernment of the right context for the techniques - becomes even more critical for understanding how leaders respond when faced with problems. This book, therefore, not only addresses how to demonstrate judgment, but also deals with questions regarding under what conditions judgment is most vulnerable and under what situations leaders are most likely to be in conflict about what is considered the "right" judgment.

Leadership scholars answer questions about the how, when, and where of judgment from significantly different viewpoints. In this edited volume, we showcase the diversity of thought on judgment and leadership to extend existing understanding and offer new insights. The volume will appeal to scholars, instructors, and others who focus on leadership, including organizational behavior, management, human resource management, higher education, and organizational development. Anyone interested in how leaders form, practice, and develop judgments will find the book an invaluable collection of the latest thinking on the topic.

\section{THEMES ON JUDGMENT AND LEADERSHIP COVERED IN THE BOOK}

The volume highlights concepts that are novel to many readers. For example, judgment involves deciphering "seeds versus weeds" (Chapter 6), invokes "dirty hands" (Chapter 9), and requires navigating "disjunctures" (Chapter 13). Judgment can be illustrated through 
a leader's response to "cosmology episodes" (Chapter 11), monitored through subtle eye tracking (in controlled settings) (Chapter 10), and captured in justification circuits (Chapter 5). The insights are often provocative, such as the idea that a better understanding of judgment comes through an analysis of leadership in the context of totalitarianism (Chapter 4).

Familiar ideas are reinterpreted. For example, Aristotle's notion of phronesis, often translated as practical wisdom, is a theme that appears in multiple chapters of the book as a way to understand how leaders exercise judgment. This book reinforces the contemporary relevance of terms like phronesis. Cognitive skills play a key role in our understanding of judgment (Chapter 2) as leaders navigate the complexity associated with ill-structured problems (Chapter 15). Even with the tools at leaders' disposal, judgment remains a "best guess" in a complex world (Chapter 7).

Other themes suggest that judgment requires an understanding of a leader's metacognitive processes (e.g., judgments about judgments). Judgment requires leaders to exercise both self-knowledge (Chapter 12) and knowledge of others. Character is key to judgment (Chapter 3). Leaders build judgment through experience as well as through formal education (Chapter 14). At the same time, leadership requires understanding that too much experience, or the wrong experience, can breed hubris (Chapter 8 ) and degrade judgment.

What is not found in this book is also noteworthy. The academic study of judgment has been dominated by quantitative approaches to judgment, often captured under the heading of judgment and decision-making (see, for example, Bazerman, 2002). While quantitative approaches deserve recognition, we believe this is well-covered territory. Even quantitative data are open to interpretation, representation, and rationalization. This volume, therefore, takes the deliberate position that discernment of data is more important than computation. This does not suggest the book is devoid of systematic study grounded in the behavioral and social sciences. In fact, several authors introduce studies and recommend future directions for the study of judgment and leadership based on systematic studies. Indeed, laboratory studies from psychology or neuroscience, qualitative readings, and content analysis, as well as cross-sectional studies conducted in organizations, all provide foundational insights. Yet we focus here on how systematic study informs our overall understanding of the relationship between judgment and leadership.

In discussions of judgment, everything is open for deliberation. Even the spelling of the term meets with disagreement. We have chosen the more common usage in the United States, "judgment," for the title. The alternative spelling "judgement," also a widely accepted term in British English, is used within some of the chapters. This illustrates a larger theme of the book, understanding judgment as a multidisciplinary study.

Definitions of judgment vary throughout the book as well. More than half a century ago, Herb Simon recognized the challenges of coming up with a unified approach to judgment. In organizations, multiple individuals formulate problems, which leaves evaluation and implementation of problems and their solutions open to interpretation from multiple perspectives (March and Simon, 1958). Negotiation and power dynamics within the organization shape what constitutes a "right decision," and the right interpretation of evidence shifts over time (Trank, 2014). Definitions of judgment vary greatly, from focusing on epistemological concerns (Shotter and Tsoukas, 2014) or moral uncertainty (Kohlberg, 1969) to more decidedly rationalist perspectives (Rousseau, 2012). 
We also acknowledge the difficult times during which this volume was composed. Many if not all of the authors wrote their chapters during the COVID-related lockdown and subsequent containment. These events played an obvious role in the minds of several authors, and they view judgment through the shadow of the COVID epidemic.

In addition to the necessary focus on COVID-related examples, the chapters rely on a host of examples that inform our understanding of judgment and leadership. The book features political leaders, U.S. federal law enforcement officers, business leaders, and university administrators, among others. Multiple references to current and historical events serve as cautious reminders that a leader's judgment can come with real consequences. Examples of leaders exercising (good and bad) judgment include George Floyd's death, a CNN news crew being arrested, seven people shot in Louisville protesting George Floyd's death, accusations of espionage and violation of Hong Kong's freedom, terminating relations with the World Health Organization, Enron and the financial crisis of 2008, the lead up to and continuation of the war in Iraq, the shootdown of Malaysian Air Flight MH17, the politics of aid bills to address the economic consequences of the COVID-19 pandemic, and climate change denial.

\section{CONTRIBUTIONS TO THE BOOK}

Todd, Newbold, and Mumford, in the chapter "Cognition Counts: Cognitive Skills Contributing to Leader Judgment," emphasize leaders as master problem-solvers, those who are willing to take on and solve problems that others cannot. They emphasize cognitive skills and their influence on performance outcomes. Judgment means judging "the adequacy of the given problem solution." Nine skills are offered: (1) problem definition, (2) cause/goal analysis, (3) constraint analysis, (4) planning, (5) forecasting, (6) creative thinking, (7) idea evaluation, (8) wisdom, and (9) sensemaking.

These cognitive factors can be measured and, thus, leaders find a ready set of tools to help them develop these skills. The authors also mention that the list of nine cognitive skills is not exhaustive and take the position that an emphasis on individual leadership rather than social skills may be the most valuable in discussions of judgment. The chapter provides an engaging set of variables that help frame the overall discussions of judgment that follow in later chapters.

Nguyen and Crossan, in their chapter "Character-Infused Judgment and Decision Making," make the case for including virtue ethics and character in discussions of judgment. The extensive research on judgment and decision-making provides deep insights into judgment and leaders, but research that relies on rational decision-making in the form of probabilities, measurements, and other quantitatively driven processes is inferior to character-driven judgment given the answers leaders need when facing real-life situations. Judgment and decision-making is like a blunt instrument that can be used to achieve a goal. It says little about what goals the leader should be achieving, nor does it address the role of ethics in pursuit of the goal. Character is important because it helps guide leaders in both the development and practice of judgment.

Nguyen and Crossan describe a variety of character-based habits associated with the character-infused leader, including transcendence, drive, collaboration, humanity, humility, integrity, temperance, justice, accountability, and courage. The leader can learn to cultivate character, but the leader needs to be aware of the need to learn and must be intentional about developing these character-based habits. 
Gardiner and Fulfer's chapter, "The Judgment of Arendt," shows how the philosophy of Hannah Arendt can help us understand judgment and leadership in the context of mandated use of masks as a preventive measure for the spread of COVID. Arendt's concerns were primarily about the rise and acceptance of totalitarianism in Europe. Yet, in the chapter, themes emerge that relate to current times: Former president Donald Trump was reported to have considered instituting martial law in order to remain in power.

Gardiner and Fulfer's reading of Arendt sheds light on our thinking about judgment and leadership. Lack of judgment is not the result of evil but banality, a lack of empathy for others. Judgment results from courage and the ability to consider the viewpoint of others. Leaders are representative of a "collective political experience." Judgment is born through years of experience, which is held up for judgment by followers, as such judgment results when a leader tries to understand the perspective of others. Thus, leadership judgment results from thinking about process (rather than simply about outcomes), considering diverse viewpoints, and engaging in reflective practice. This chapter highlights how philosophy can help us understand the basic assumptions associated with how we view a leader's judgment and evaluate its value.

Kornprobst, in "Judgments and Justifications," considers COVID and leadership in terms of the consequences of leaders' judgments. He frames the chapter in terms of judgment in international political leadership and its role in consequential policy and political decisions. Leaders, like all humans, work within various limitations. Leaders have free will, but that free will is caught up in "circuits" that are capped by prejudgments, taken-for-granted assumptions, and justifications of actions. Kornprobst argues against discipline-specific reasoning, explaining that judgment involves identifying "repertoires" of possible judgments that are social in nature and not discipline specific, "justifying" or communicating those judgments to others and one's self, and developing structures that support those justifications.

Kornprobst argues that because of the complexity associated with leadership, both leader and follower remain in flux about the right judgment. To be a leader (or a follower, for that matter) requires accepting the constant shifting interpretations of judgments and justifications. We might find that our judgments of leaders appear inconsistent, especially if we apply a rationalist lens. However, our search for consistency will be futile if we don't consider the vast influences and ever-changing nature of what we evaluate as good judgment.

Murugavel and Reiter-Palmon, in "How Leaders Judge Creativity: A Look into the Idea Evaluation Process," describe judgment as a creative process tied to innovation. At its core, judgment is understood by distinguishing "seeds versus weeds." Seeds are those innovative ideas that can flourish in an organization, and weeds are those ideas that are less likely to foster real long-term sustainable innovation. Judgment involves being able to distinguish between the two and is demonstrated in a process called "idea evaluation," which in turn is a subprocess of creative problem-solving.

Murugavel and Reiter-Palmon emphasize evaluating the outcome of leadership judgment by considering judgment as a dependent variable. This chapter provides an example of how we might evaluate outcomes that are associated with judgment in leaders through forecasts. Forecasts involve several dimensions; creativity, thinking, accuracy, and implementation are a few of the potential outcomes we might use to evaluate leaders on their judgment. Leaders, managers, and others exercise judgments that can be evaluated primarily by the future outcomes of their judgments. A partial list of variables to consider when evaluating judgment includes individual characteristics, individual states, and situational influences. 
Sullivan, in the chapter "Judgment and Decision Making: A 'Brain-First' Perspective," provides a practice-inspired research agenda on judgment from a brain perspective. Despite the growing influence of neuroscience research in judgment, the extensive findings in this area have been slow to influence our understanding of leadership and judgment. Sullivan provides a path forward. Of particular help in integrating brain science with judgment is his focus on dynamic systems. The benefit of using a dynamic systems perspective is that it offers an alternative to the reductionism that plagues much of the neuroscience field. The brain is primary, according to Sullivan's brain-first approach, but it operates within a complex system. Importantly, it is how we make judgments in a team context that offers the most insight into judgment. Through the eyes of neuroscience, judgment needs to be understood in light of the emotional content of judgment, not just rational thinking.

His chapter brings up a fascinating yet simple question: What effect do physical factors and the status of various bodily functions have on judgment? He ultimately suggests that stress, focus, self-regulation, heart rate variability, and even hydration can help us understand the connection between judgment and leadership.

In his chapter, "Hubris, Bad Judgement, and Practical Wisdom in Politics and Business," Sadler-Smith is concerned with hubris, simply stated as leaders' overconfidence in their own ability to exercise judgment. Hubris is important for judgment because judgment, as a form of decision-making and action-taking in the face of ambiguity, often leads to disastrous consequences: the market crash of 2008, the invasion of Iraq, the handling of COVID-19, and multiple business examples. The thing about hubris is that it is acquired over time. As they acquire more and more power, leaders may be at particular risk. What might start as desirable traits, such as ambition and a desire for influence, become excessive over time. Ultimately, lapses in judgment ensue. In this way, hubris is viewed as an excess of leadership, where desirable qualities may go too far, resulting in impaired judgment.

Leaders overcome hubris by balancing excess and deficiency. Too much of the stuff that makes up good leadership (e.g., the desire for change, the need for power, and confidence and striving) can lead to bad judgments. But failure to have enough of the good stuff means being ineffective and perhaps even failing to achieve status as a leader at all. When leaders get the formula right, they are more likely to move in the direction of good judgment.

Price, in "Feeling and Dirty Hands: The Role of Regret Experienced by Responsible Agents," addresses justification of past actions in light of a leader's own sense of responsibility for the consequences of those actions. He invokes the notion of "dirty hands," the situation where a leader makes the "right" or desirable judgment, but the judgment is morally wrong at the same time. Price makes a promising proposition that requires some paradoxical thinking. The dirty hands phenomenon occurs when leaders contemplate a past judgment. Dirty hands leave leaders feeling regret that they had to take the action. But they also remain convinced that the action was necessary. Thus, dirty hands suggest that a judgment can be both morally wrong and defensible at the same time. Adding to the paradox, leaders often fail to experience regret. They find it easier to convince themselves that they were justified in their action than to struggle with the consequences. When leaders include in their process of making judgments "defense of others and the consent of followers," they come closer to exercising exemplary judgment.

As with other chapters, Price makes note of the importance of context in making judgments. Committing an immoral act such as murder is different than the moral transgression associated 
with making a business or political deal that you never intend to fulfill. Leaders must learn to navigate the moral ambiguity inherent in the power and politics associated with leadership. Thus, leadership requires making judgments in light of multiple competing (moral) commitments. Further, the role one plays in an organization (e.g., a faculty member versus an administrator, employee versus CEO) may bind the leader in some way to different moral obligations (e.g., the welfare of individual students versus the welfare of an institution).

Pittarello and Foti, in "Context Corrupts: What Makes Leaders Fail to See Their (Mis) behaviors," also consider the ethical elements associated with leaders and their judgments. They show connections between judgment and leadership and behavioral ethics, the study of closely observed behaviors associated with making ethical choices. Here, judgment is a social-cognitive balancing act, say between maintaining a positive self-concept of oneself as honest while simultaneously engaging in activity that is dishonest.

Pittarello and Foti reveal data about how and when leaders justify judgments. They present the results of a number of laboratory studies that provide an excellent example of how methods such as eye tracking can enhance understanding of judgment. In one study, they identify the information that leaders pay attention to and what they ignore when making judgments. This captures not just how leaders reach judgments, but how they justify these judgments retroactively.

In their chapter, "Resilience Leadership Judgment: Findings from a Cosmology Episode Study of the Shootdown of Flight MH17," O'Grady, Moorkamp, Torenvlied, and Orton conduct a detailed analysis of the shootdown of Malaysian Air Flight MH17 and the subsequent government response. The study shows how variants of sensemaking are associated with judgment and the importance of judgment in extreme situations. They discuss "cosmology episodes," situations that become senseless, in the sense that sense is no longer a given. But even when sense no longer exists, leaders must still sensibly find ways to exercise judgment. The words are important. The word cosmology provides the sense that the universe as the leader knows it no longer seems to exist. At the same time, the word episode suggests that the situation offers a comfortable range of possible sensible judgments in which the world can be made meaningful. This also implies that the range of meaning is limited, or bracketed, by a leader's capacity for judgment.

The study shows that crises are not always easily detected in pre-crisis events and that judgments are as much about retrospective consideration as future anticipation. Discipline-specific knowledge seldom provides enough background to make sense of crisis. These are just a few of the counterintuitive insights found in the chapter.

Ang, Rockstuhl, and Christopoulos, in "Cultural Intelligence and Leadership Judgment \& Decision Making: Ethnology and Capabilities," propose a model of leadership judgment based on cultural intelligence. Leaders do not just shape culture; a leader's judgment is shaped by culture as well. They outline four capabilities for improving judgment in leadershipmotivational, cognitive, metacognitive, and behavioral-which in turn comprise six leadership processes that are tied to judgment: formulating a vision, communicating the vision, planning and budgeting, designing the organizational structure, influencing and motivating, and monitoring and controlling.

While Ang, Rockstuhl, and Christopoulos emphasize the generalizability of their model, they take important steps to show the cultural element associated with each process. The model contributes to understanding leadership judgment by suggesting clear competencies 
that leaders can develop to exercise better judgment. This moves the discussion of leadership, culture, and judgment from discussions of "cultural comparison" to "intercultural capabilities."

In "Disjuncture and Development: A Learning Theory Approach to Leadership Judgement," Saunders sharpens our focus on how a leader's "guiding principles" impact judgment. The problem (although Saunders does not really state this as a problem to overcome) is that leaders are often unconscious of their own guiding principles, unaware of the values driving their judgment. Only with intervention or deep reflection do these guiding principles become explicit in the minds of the leaders. The underlying guiding principles of judgment, therefore, are unconscious and tacit, and only by making them explicit can a leader improve judgment.

Writing from the perspective of adult learning, Saunders reviews the various contributions that adult learning theory makes to our understanding of judgment. The emphasis is on the development of judgment, or as Saunders asks, "How do leaders learn to lead?" Experiences, especially those of "disjuncture," when leaders realize they don't know something, form the basis of our judgment.

Eriksen, in 'On Facilitating the Development of Leaders' Ability to Exercise Good Judgment," sees relationships as essential for judgment. In one study he conducted, he quotes a federal worker who discussed exercising judgment in the context of relationships and in concert with others in a constantly changing situation or circumstance. Eriksen emphasizes not only the developmental nature of judgment (judgment is something leaders are continually learning), but also the existential nature of judgment (judgment is something that is inseparable from who the leader $i s$ ). Eriksen describes how his approach to judgment informs his teaching and provides a narrative account of how he helps students realize their own capacity for judgment.

Kayes and Kayes, in "Improving Leader Judgment through Experiential Learning," also offer a look at how judgment is learned from experience. Their approach is prescriptive and suggests a model to bridge the academic/practice divide when it comes to learning judgment. They describe a four-process model (with several subprocesses) that helps students learn to exercise judgment in a classroom setting, but that can also be applied in more practical settings, such as the workplace. As in Saunders's chapter, the perspective is adult learning theory, but Kayes and Kayes embed their approach more specifically in Kolb's experiential learning theory and the learning cycle. One of their goals is practical: to provide a model to guide students as they exercise judgment, mainly to improve it as they face more complex problems. Another goal is theoretical: to advance ideas associated with teaching and learning judgment.

In summary, these chapters capture the diversity of perspectives that make up the multidisciplinary study of judgment and leadership. Readers will be rewarded with new insights into how judgment is conceived, how leaders exercise judgment, what prevents judgment, and how leaders learn judgment. Taken as a whole, these chapters show that leaders need to reach beyond their disciplinary training and limited experience to improve judgment. By viewing judgment from multiple perspectives, the contributors reveal the significance of judgment as a leadership process, which will further invigorate the study of judgment and leadership.

\section{REFERENCES}

Akinci, C., and Sadler-Smith, E. (2019). Collective intuition: Implications for improved decision making and organizational learning. British Journal of Management, 30(3), 558-577. https://doi.org/10.1111/ 1467-8551.12269. 
Bazerman, M. (2002). Judgment in managerial decision making (5th ed.). Wiley.

Carter, L., II. (2013). Developing expertise in management decision making. Academy of Strategic Management Journal, 12(1), 21-37.

Dewey, J. (1933). How we think: A restatement of the relations of reflective thinking to the educative process. Heath.

Ericsson, K. A., and Lehmann, A. C. (1996). Expert and exceptional performance: Evidence of maximal adaptation to task constraints. Annual Review of Psychology, 47(1), 273-305. https://doi.org/10.1146/ annurev.psych.47.1.273.

Errington, A., and Bubna-Litic, D. (2015). Management by textbook: The role of textbooks in developing critical thinking. Journal of Management Education, 39, 774-800. https://doi.org/10.1177/ 1052562915594839 .

Franklin, C. L., II. (2013). Developing expertise in management decision-making. Academy of Strategic Management Journal, 12(1), 21-37.

Graduate Management Admissions Council. (2016). Integrated reasoning: Critical skills for today's business environment. http://www.gmac.com/market-intelligence-and-research/research-insights/ curriculum-and-delivery/integrated-reasoning.aspx.

Klein, G. (2015). A naturalistic decision making perspective on studying intuitive decision making. Journal of Applied Research in Memory and Cognition, 4, 164-168. https://doi.org/10.1016/j.jarmac .2015.07.001.

Kohlberg, L. (1969). Stages and sequences: The cognitive-developmental approach to socialization. In D. A. Goslin (Ed.), Handbook of socialization theory and research (pp. 347-380). Rand McNally.

Kolb, A., and Kolb, D. (2005). Learning styles and learning spaces: Enhancing experiential learning in higher education. Academy of Management Learning and Education, 4, 193-212. https://doi.org/10 .5465/amle.2005.17268566.

March, J. G., and Simon, H. A. (1958). Organizations. John Wiley \& Sons.

Mintzberg, H. (2004). Managers, not MBAs. Pearson Education.

Rousseau, D. M. (Ed.). (2012). The Oxford handbook of evidence-based management. Oxford University Press. https://doi.org/10.1093/oxfordhb/9780199763986.001.0001.

Schon, D. A. (1983). The reflective practitioner: How professionals think in action. Basic Books.

Shotter, J., and Tsoukas, H. (2014). In search of phronesis: Leadership and the art of judgment. Academy of Management Learning and Education, 13, 224-243. https://doi.org/10.5465/amle.2013.0201.

Simon, H. (1973). The structure of ill-structured problems. Artificial Intelligence, 4, 181-201. https://doi .org/10.1016/0004-3702(73)90011-8.

Sternberg, R. J., Forsythe, G. B., Hedlund, J., Horvath, J. A., Wagner, R. K., and Williams, W. M. (2000). Practical intelligence in everyday life. Cambridge University Press.

Sternberg, R. J., and Hedlund, J. (2002). Practical intelligence, g, and work psychology. Human Performance, 15(1-2), 143-160. https://doi.org/10.1207/S15327043HUP1501\&02_09.

Tetlock, P. E. (1994). Integrative complexity. In M. Hewstone and A. S. R. Manstead (Eds.), Dictionary of social psychology (pp. 326-328). Blackwell.

Tichy, N. M., and Bennis, W. G. (2007a). Judgment: How winning leaders make great calls. Penguin.

Tichy, N. M., and Bennis, W. G. (2007b). Making judgment calls. The ultimate act of leadership. Harvard Business Review, 85(10), 94-102, 165.

Trank, C. Q. (2014). "Reading" evidence-based management: The possibilities of interpretation. Academy of Management Learning and Education, 13, 381-395. https://doi.org/10.5465/amle.2013 .0244 .

Vickers, G. (1984). Judgment. In G. Vickers and The Open Systems Group (Eds.), The Vickers papers (pp. 230-245). Harper \& Row.

Wittmer, D. W., and Fukami, C. V. (2017). Educating future business leaders to be practically wise: Designing an MBA curriculum to strengthen good decision-making. In O. Gunnlaugson and W. Kupers (Eds.), Wisdom learning: Perspectives on wising up in management education (pp. 229-247). Routledge. 